\title{
A Security Framework for E-Business Applications
}

\author{
Anuradha Sharma \\ Dept. of Computer Science \\ Amity University, Lucknow campus
}

\author{
Puneet Misra \\ Asst.Prof, Dept. of Computer Science \\ Lucknow University, Lucknow
}

\begin{abstract}
During the electronic business, the clients and the merchants make use of the internet. Thus, we can say that the internet, the client, and the merchant are the components for the electronic business. The Electronic Business involves various categories of businesses. These various types of e-businesses have different types of security requirements to keep the businesses secure. The threats to these types of businesses prohibit people from believing on them. Except highly educated, people often do not take much interest in believing much on the services provided by e-businesses because of the problems of security in doing these types of businesses. We are proposing here a framework that can be implemented on various categories of e-business so that it can be trusted by most of the people. The framework can be used to define the possibilities of threats for the various categories. Using these possibilities, it is possible to give a prediction of the level of security needed for these categories.
\end{abstract}

\section{Keywords}

Ttransaction, threats and vulnerabilities

\section{INTRODUCTION}

E-business is defined as business connections, which make use of electronic media ${ }_{[2]}$. One of the major characteristics of e-business is that prior to the business interaction, partners do not necessarily have to know each other ${ }_{[3]}$. E-business has not grown to its full potential despite its wide use and opportunities. One of its most important obstacles for this is the lack of proper security measures as well as difficulties to specify adequate security requirements. There are plenty of researches about security in e-business. The final report of the SEMPER (Secure Electronic Market Place for Europe) project can be considered as a reference to this topic ${ }_{[4]}$.

E-business or electronic business is not only limited to buying and selling of goods over the internet. E-business includes using internet to provide better customer service, streamline business process, increase sales and reduce cost of the business for the customer as well as the organization. IBM first used the term e-business in October 1977. Since then, companies are using internet to cut cost and provide better customer service.

E-business is able to benefit all types of businesses. Ebusiness is not restricted to technology-related products and services. It permits companies in every field to do their business online. E-business can be applied to any part of a company's operations through networking. These operations include marketing and sales, production, purchasing and logistics, design and engineering etc. When several of these functions are combined then e-business is most effectively used.

\section{TRANSACTION}

Transaction simply means an instance of buying and selling something. A transaction consists of a unit of work in a database management system against a database which is in general independent of other transactions. The transaction has to complete in its entirety in order to make the database changes permanent. The transaction should be atomic, consistent, isolated and durable.

\section{ISSUES IN TRANSACTION SECURITY}

The transactions in case of e-business have tree major constituents viz. the client computer, the communication medium, and the web and commerce servers. The security can be penetrated at either of the three parts.

The types of security that must be enforced at each of the levels varies. There are different types of threats at each of these levels which are-

\subsection{Client Threats}

Web pages were generally static until the popularity of active web content. Static web pages were coded in HTML and could do little more than display content and provide links to related pages with additional information. The use of active content has changed this perception. In case of e-business, dynamic pages are of much importance.

3.1.1. Active content $T_{1}$ : Programs that are embedded transparently in web pages and that cause an action to occur are referred to as active content. Active content can be moving graphics, download and play audio, or even more. The use of active content in e-commerce is to place one's required items into a shopping cart and to compute the total invoice amount, including sales tax, handling, and shipping costs. Java applets, ActiveX controls, JavaScript, and VBScript are some popular active content forms.

Anyone can embed malicious active content in web pages, since active contents are transparent to users. This delivery technique immediately begins executing and taking actions that are harmful and is called Trojan Horse.

Because the internet is stateless and cannot remember a response from one web page view to another, cookies help solve the problem of remembering customer order information or usernames or passwords. Cookies are special files that are created automatically. Malicious active content delivered by means of cookies can reveal the contents of client-side files or even destroy files stored on client computers.

3.1.2. Malicious codes $T_{2}$ : Malicious code can be a computer virus, worm or trojan horse. A trojan horse is a program which performs a useful function, but performs an 
unexpected action as well. Virus is a code segment which replicates by attaching copies to existing executables. A worm is a program which replicates itself and causes execution of the new copy. Anyone or all of these can create havoc on the client side once executed.

\subsubsection{Server-side masquerading $T_{3}$ : Masquerading or} spoofing is an impersonation of one entity by another. It lures a victim into believing that the entity with which it is communicating is a different entity. For example, if a user tries to log into a computer across the internet but instead reaches another computer that claims to be the desired one, the user has been spoofed.

\subsection{Communication Channel Threats}

The internet links a consumer (client) to an e-commerce resource (commerce server). Messages from the sender travel a random path through a number of intermediate computers on the network before reaching the final destination. During this transmission, it is impossible to guarantee that every computer on the internet through which messages passes, is safe and secure.

3.2.1. Confidentiality threats $T_{4}$ : Confidentiality means preventing disclosure of unauthorized information. Confidentiality breaching on the internet is not difficult.

\subsubsection{Integrity threats $T_{5}$ : Integrity refers to the} trustworthiness of data or resources, and refers to preventing improper or unauthorized changes. An integrity threat exists when an unauthorized party can alter a message stream of information. The banking transactions that are not protected are subject to integrity violations.

3.2.3. Availability threats $T_{6}$ : Availability is the ability to use the information or resource desired. The purpose of availability threats, also known as delay or denial threats, is to disrupt normal computer processing or to deny processing entirely.

\subsection{Server Threats}

The third link in the client-internet-server trio is the server which completes the e-business path between the user and a commerce server. Anyone can cause destruction and acquire information illegally as the Servers have vulnerabilities.

\subsubsection{Web-server threats $T_{7}$ : The function of web-} server software is to deliver web pages by responding to HTTP requests. Web-server software is designed with web service and convenience as the main design goal. The probability that it may contain coding errors (bugs) and security holes or security weaknesses increases with the increase in the complexity of the software.

3.3.2. Commerce server threats $T_{8}$ : The commerce server and the web-server respond to requests from web browsers through the HTTP protocol and CGI scripts. The commerce server software comprises several pieces of softwares like FTP server, a mail server, a remote login server, and operating systems on host machines. Each one of these can have bugs.

3.3.3. Database threats $T_{9}$ : E-commerce systems maintain a database containing user data and also retrieve product information from other databases connected to the web-server. These databases contain product information as well as valuable and private information. This private information could damage the security of a company if it were disclosed or altered. Some databases store username/password pairs in a non-secure way. One can reveal private and costly information if he obtains user authentication information.

3.3.4. Common gateway interface threats $T_{10}$ : The task of common gateway interface (CGI) is to transfer information from a web-server to another program. Active content to web pages is provided by CGI and the programs to which they transfer data. Since CGIs are programs, they can be misused and be a security threat.

3.3.5. Password hacking $T_{11}$ : The password-based system has the biggest threat of being guessed. Access to the complement, the complementation functions, and the authentication functions have to be obtained for guessing the password. While guessing the password, if none of these have changed, then the attacker can use the password to access the system $_{[1]}$

In case of e-business, there are some other threats also which cannot be left without consideration

\subsection{Repudiation of Origin $\mathbf{T}_{\mathbf{1 2}}$}

It is a false denial that an entity sent (or created) something. For example, suppose a customer orders a product y sending a letter agreeing to pay the amount. The vendor ships the product and demands the payment. The customer denies to have ordered the product and by the law is entitled to the unsolicited shipment without payment. The customer has repudiated the origin of the letter. If the vendor fails to prove that the letter came from the customer, the attack succeeds.

\subsection{Denial of Reciept $\mathbf{T}_{\mathbf{1 3}}$}

A false denial that an entity received some information or message, is a form of deception. For example, suppose a customer orders a product, and the vendor asks to pay the cost before delivery. The customer pays the cost and receives the shipment. The customer then asks when he will receive the product, the question constituents a denial of receipt attack.

\subsection{Delay $T_{14}$}

It is a temporary inhibition of service. The delivery of a message or service requires some amount of time and if an attacker can force the delivery to take more than the time the attacker has delayed the delivery.

\subsection{Denial of Service $\mathbf{T}_{\mathbf{1 5}}$}

It is a long-term inhibition of a service. The attacker prevents a server from providing a service. Denial of service poses the same threat as an infinite delay.

\section{APPLICATIONS OF E-BUSINESS/ WHO ARE INVOLVED IN BUYING/SELLING ON THE INTERNET IN INDIA}

\subsection{Electronic Banking}

Several financial management software packages exist such as Quicken, Microsoft Money and Peachtree. Personal Management through these software packages requires duplication of efforts, i.e. once the financial institution and once by the user. With the wide availability and access of the 
internet, electronic banking empowers the customers to access their accounts, carry out transactions through web browsers or web enabled personal software packages, thus, keeping both of them in synchronization. Customer finds it very suitable to view account details, transfer funds, pay bills, order checks, and review account history.

\subsection{Marketing}

Internet and electronic commerce technologies have been utilized in mitigating some of the problems of traditional commerce. Internet enabled marketing is not an alternative to traditional marketing, but has emerged as a good augmenting mechanism. Internet is very interactive and the marketing communication is not one way anymore. Internet can be used as a media by itself for delivering communication including advertisement.

\subsection{Electronic Trading}

Electronic trading is a mechanism that utilizes the power of electronics and communication media (internet) to bring together geographically dispersed buyers and sellers on a virtual common trading platform. The common platform offers aggregated information to all participants in a fair manner. The platform facilitates access to aggregate information, order booking, and fulfillment.

\subsection{E-Governance}

E-governance simply means technology driven governance. In e-governance, information and communication technology (ICT) is used for delivering government services. It also involves exchange of information communication transactions, integration of various stand-alone systems and services between government-to-citizens (G2C), governmentto-business (G2B), government-to-government (G2G), and also the back office interactions and processes within the entire government framework ${ }_{[14]}$

\subsection{Education}

Education is the first priority of any individual or family. Amongst the latest which promote education, internet comes the first. Virtual education is a new milestone in this field. It refers to the type of learning in which the learner and the teacher interacts through the use of technology such as video conferencing, internet or other multimedia resources. Internet is not only used for opening websites or making friends through social networking sites, but it is a source of knowledge and information for every type of education.

\subsection{Health}

Internet has made it very easy for people to gain knowledge about various diseases and their cures. People can get health tips from doctors through the use of video conferencing. Distance is no barrier by the use of internet and it plays a great role in the area of individual's health.

\section{ADDITIONAL DIMENSIONS}

The third dimension of the framework is the site used. The following three sites are typical for a simple e-business because of its distributed nature:

- merchant's site (M),

- customer's site(C), and

- transmission way (the Internet).

This distinction has been used and analyzed in [5] and [6]. The security requirements of the transmission way i.e. internet may vary. Since many other parties such as network providers, telecommunication companies, hardware and software companies, etc. may be involved in between, a customer or merchant may probably not have the means to change the structure of security mechanisms outside their domains ${ }_{[7]}$.

\section{DIMENSIONS OF THE FRAMEWORK}

This paper focuses on a general security framework for the ebusiness. This framework consists of three dimensions. These dimensions are types of e-business, types of threats and the people/parties involved in the e business.

The types of various dimensions in our case would be the elements of the framework.

The above mentioned sections have defined the major dimensions of our framework and the various elements relevant for every dimension. The framework is open in nature that is, it can be adjusted by adding or removing the dimensions or the elements.

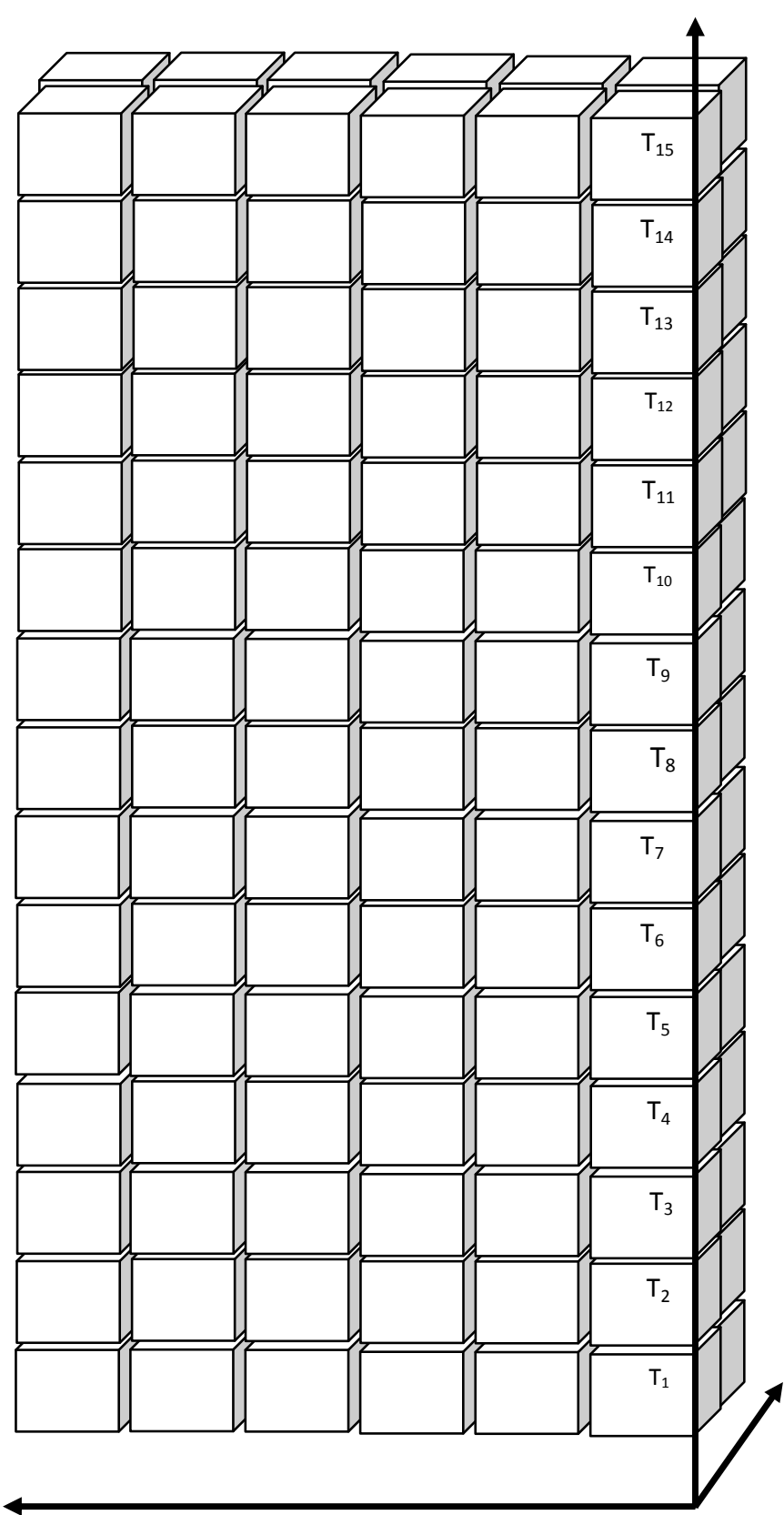


A checklist can be defined that contains which type of threat is applicable to a particular category of e-business.

Table1:Checklist for types of e-business and types of threats

\begin{tabular}{|l|l|l|l|l|l|l|}
\hline $\begin{array}{l}\text { Busin } \\
\text { ess } \\
\text { threat } \\
\mathrm{s}\end{array}$ & $\begin{array}{l}\text { E- } \\
\text { Bank } \\
\text { ing }\end{array}$ & $\begin{array}{l}\text { Marke } \\
\text { ting }\end{array}$ & $\begin{array}{l}\text { E- } \\
\text { Tradi } \\
\text { ng }\end{array}$ & $\begin{array}{l}\text { E- } \\
\text { Govern } \\
\text { ance }\end{array}$ & $\begin{array}{l}\text { Educat } \\
\text { ion }\end{array}$ & $\begin{array}{l}\text { Hea } \\
\text { th }\end{array}$ \\
\hline$T_{1}$ & $\sqrt{ }$ & $\sqrt{ }$ & $\sqrt{ }$ & $\sqrt{ }$ & $\sqrt{ }$ & $\sqrt{ }$ \\
\hline$T_{2}$ & $\sqrt{ }$ & $\sqrt{ }$ & $\sqrt{ }$ & $\sqrt{ }$ & $\sqrt{ }$ & $\sqrt{ }$ \\
\hline$T_{3}$ & $\sqrt{ }$ & $\mathrm{x}$ & $\sqrt{ }$ & $\sqrt{ }$ & $\sqrt{ }$ & $\sqrt{ }$ \\
\hline$T_{4}$ & $\sqrt{ }$ & $\mathrm{x}$ & $\sqrt{ }$ & $\sqrt{ }$ & $\mathrm{x}$ & $\mathrm{x}$ \\
\hline$T_{5}$ & $\sqrt{ }$ & $\sqrt{ }$ & $\sqrt{ }$ & $\sqrt{ }$ & $\sqrt{ }$ & $\mathrm{x}$ \\
\hline$T_{6}$ & $\sqrt{ }$ & $\mathrm{x}$ & $\sqrt{ }$ & $\sqrt{ }$ & $\mathrm{x}$ & $\mathrm{x}$ \\
\hline$T_{7}$ & $\sqrt{ }$ & $\mathrm{x}$ & $\sqrt{ }$ & $\sqrt{ }$ & $\mathrm{x}$ & $\mathrm{x}$ \\
\hline$T_{8}$ & $\sqrt{ }$ & $\mathrm{x}$ & $\sqrt{ }$ & $\sqrt{ }$ & $\mathrm{x}$ & $\mathrm{x}$ \\
\hline$T_{9}$ & $\sqrt{ }$ & $\sqrt{ }$ & $\sqrt{ }$ & $\sqrt{ }$ & $\sqrt{ }$ & $\sqrt{ }$ \\
\hline$T_{10}$ & $\sqrt{ }$ & $\sqrt{ }$ & $\sqrt{ }$ & $\sqrt{ }$ & $\sqrt{ }$ & $\sqrt{ }$ \\
\hline$T_{11}$ & $\sqrt{ }$ & $\sqrt{ }$ & $\sqrt{ }$ & $\sqrt{ }$ & $\sqrt{ }$ & $\sqrt{ }$ \\
\hline$T_{12}$ & $\sqrt{ }$ & $\sqrt{ }$ & $\sqrt{ }$ & $\sqrt{ }$ & $\mathrm{x}$ & $\mathrm{x}$ \\
\hline$T_{13}$ & $\mathrm{x}$ & $\sqrt{ }$ & $\sqrt{ }$ & $\sqrt{ }$ & $\mathrm{x}$ & $\mathrm{x}$ \\
\hline$T_{14}$ & $\mathrm{x}$ & $\mathrm{x}$ & $\sqrt{ }$ & $\sqrt{ }$ & $\sqrt{ }$ & $\sqrt{ }$ \\
\hline$T_{15}$ & $\mathrm{x}$ & $\mathrm{x}$ & $\sqrt{ }$ & $\sqrt{ }$ & $\mathrm{x}$ & $\mathrm{x}$ \\
\hline & & & & & & \\
\hline
\end{tabular}

\section{PROBABILITIES OF THREATS FOR VARIOUS CATEGORIES OF E- BUSINESS}

The probabilities of the aforementioned threats for various categories of e-business can be tabulated. Since the probabilities vary from 0 to 1 , the probabilities can be considered as $\operatorname{high}(0.9)$, medium(0.5), and low(0.1). Probability 0.9 indicates that the concerned party, i.e. the client and the merchant for a particular category considers the security objective as essential. Probability 0.5 indicates that the party wants the security objective to be protected. Probability 0.1 indicates that the concerned party has no particular interest in the security objective [6]. The probabilities of various categories of threats can be summarized in table2. This metrics can further define the level of security needed for various category of e-business

Table2:Probability for types of e-business and types of threats

\begin{tabular}{|l|l|l|l|l|l|l|}
\hline $\begin{array}{l}\text { Busin } \\
\text { ess } \\
\text { threat } \\
\mathrm{s}\end{array}$ & $\begin{array}{l}\text { E- } \\
\text { Bank } \\
\text { ing }\end{array}$ & $\begin{array}{l}\text { Marke } \\
\text { ting }\end{array}$ & $\begin{array}{l}\text { E- } \\
\text { Tradi } \\
\text { ng }\end{array}$ & $\begin{array}{l}\text { E- } \\
\text { Govern } \\
\text { ance }\end{array}$ & $\begin{array}{l}\text { Educat } \\
\text { ion }\end{array}$ & $\begin{array}{l}\text { Hea } \\
\text { th }\end{array}$ \\
\hline$T_{1}$ & 0.9 & 0.5 & 0.5 & 0.9 & 0.5 & 0.5 \\
\hline$T_{2}$ & 0.9 & 0.9 & 0.9 & 0.9 & 0.9 & 0.9 \\
\hline$T_{3}$ & 0.9 & 0.1 & 0.5 & 0.9 & 0.5 & 0.5 \\
\hline$T_{4}$ & 0.9 & 0.1 & 0.5 & 0.9 & 0.1 & 0.1 \\
\hline$T_{5}$ & 0.9 & 0.9 & 0.9 & 0.9 & 0.5 & 0.1 \\
\hline$T_{6}$ & 0.9 & 0.1 & 0.5 & 0.9 & 0.1 & 0.1 \\
\hline$T_{7}$ & 0.5 & 0.1 & 0.5 & 0.5 & 0.1 & 0.1 \\
\hline$T_{8}$ & 0.9 & 0.1 & 0.5 & 0.9 & 0.1 & 0.1 \\
\hline$T_{9}$ & 0.9 & 0.9 & 0.9 & 0.9 & 0.9 & 0.9 \\
\hline$T_{10}$ & 0.9 & 0.5 & 0.5 & 0.9 & 0.5 & 0.5 \\
\hline$T_{11}$ & 0.9 & 0.9 & 0.9 & 0.9 & 0.9 & 0.9 \\
\hline$T_{12}$ & 0.5 & 0.9 & 0.5 & 0.5 & 0.1 & 0.1 \\
\hline$T_{13}$ & 0.1 & 0.9 & 0.5 & 0.5 & 0.1 & 0.1 \\
\hline$T_{14}$ & 0.1 & 0.1 & 0.1 & 0.5 & 0.5 & 0.5 \\
\hline$T_{15}$ & 0.1 & 0.1 & 0.5 & 0.5 & 0.1 & 0.1 \\
\hline
\end{tabular}

With the help of above table, we can have an estimate of the level of threat for any particular category of e-business using the measure $\sum_{i=1}^{i=15} T_{i j}$ for different values of $j$ which represents different categories of e-business. Now, Security measure of Electronic business Application (SEBA) is:

SEBA $\alpha \sum_{i=1}^{i=15} T_{i j} ;($ for $j=1,2, \ldots \ldots ., 6)$

Therefore, above table also gives expected security level required to be enforced for a particular category of electronic business.

\section{CONCLUSION AND FUTURE SCOPE:}

The framework for the various applications of e-business has been discussed here. This is an open framework that is; the parties involved and the threats may change. Based on the parties involved and the type of organization, the threats for the organizations may change and proper security measures can be applied for conducting the e-business in a more secure way by either the customer or the merchant or both.

Further, some more categories of e-business can be included to enhance the work. This paper proposes a security measure which gives an expected security level required to be enforced on a particular category of e-business. The SEBA can be used to enforce security objective as very high, medium or low.

The SEBA can be further improved by adding more dimensions to the security measure. These dimensions can be based on a particular category of e-business application. In our case, we have not considered the communication medium. It can also be further added as a dimension in the expectation of SEBA.

\section{REFERENCES}

[1] A Sengupta,C.Mazumdar, M.S.Barik, "E-commerce Security-A Lifecycle Approach", Sadhana, vol. 30, Parts 2\&3, April/June 2005, pp. 119-140.

[2] Zwass Vladimir, "E Commerce: Structures and issues", International Journal of Electronic Commerce, 1(1):3-23, 1996.

[3] Nabil, Adam R.; Yesha, Yelena (Eds.), "Electronic commerce: Current Research issues and Applications", LNCS 1028, Springer, Heidelberg, 1996.

[4] Lacoste, G.; Pfitzmann, B.; Steiner, M.; Waidner, M. (Hrsg.), "SEMPER- Secure Electronic Marketplace for Europe”, LNCS 1854, Springer, 2000.

[5] Knorr, Konstantin; Röhrig, Susanne, "security of electronic business applications- Structure and Quantification", In: Proceedings of the 1st International Conference on Electronic Commerce and Web Technologies EC-Web 2000, Greenwich, UK, Sep. 2000, pp. 25-37.

[6] Röhrig, Susanne; Knorr, Konstantin; Noser, Hansrudi., WIRTSCHAFTSINFORMATIK， 42(2000) 6: 499-507

[7] Konstantin Knorr, Susanne Röhrig, "Security requirements of e-business processes", Volume 202 of IFIP Conference Proceedings, pages 73-86, Kluwer, 2001. 
[8] N.Smith, L.Ferreira, E. Mead, "E-Business Treands", Working Paper 2 of the E- Business and Transport Project for The National Transport Secretariat.

[9] SET Secure Electronic Transaction Specification. Book 1: Business Description, Version1.0, http://www.setco.org, 1997.

[10] O. SamySayadjari, "Multilevel Security: Reprise," IEEE Security and Privacy, vol. 3, no. 5, 2004.

[11] Lausen H.,Polleres A.,RomanD., "Web Service Modeling Ontology (WSMO)"
[12] Singh, M. P. , "Introduction to web semantics, The Practical Handbook of Internet Computing", pp29-1-2913, Chapman \& Hall/CRC2005, 2005

[13] Randy C. Marchany, Joseph G.Tront, "E-Commerce Security Issues", Proceedings of the 35th Hawaii International Conference on System Sciences - 2002.

[14] Saugata,B., and Masud,R,R.(2007, “ Implementing EGovernance Using OECD Model(Modified) and Gartner Model (Modified) Upon Agriculture of Bangladesh", IEEE. 1-4244-1551-9/07. 